\title{
Writing Strengthens Orthography and Alphabetic-Coding Strengthens Phonology in Learning to Read Chinese
}

\author{
Connie Qun Guan \\ East China Normal University and Florida State University
}

\author{
Ying Liu \\ LiaoNing Normal University
}

\author{
Derek Ho Leung Chan, Feifei Ye, and Charles A. Perfetti \\ University of Pittsburgh
}

\begin{abstract}
Learning to write words may strengthen orthographic representations and thus support word-specific recognition processes. This hypothesis applies especially to Chinese because its writing system encourages character-specific recognition that depends on accurate representation of orthographic form. We report 2 studies that test this hypothesis in adult learners of Chinese. In those studies, the researchers 1st compared the effects of an online writing tutor that included character handwriting with an instructional tutor that included reading only. The writing condition led to better performance on word recognition and on character-meaning links but not on the character-phonology link. In the 2nd experiment, we added an alphabetic (Pinyin) typing tutor to strengthen the phonology link and to control for manual motor activity during instruction. This experiment replicated the effects of writing on word recognition and charactermeaning links, whereas alphabetic (Pinyin) typing supported only phonological representations and the character-phonology link. Theoretically, the studies suggest constituent-specific effects: writing on orthography and alphabetic coding on phonology. We suggest the mechanism for the writing effect is the refinement of visual-spatial information needed for character recognition and the addition of a sensorymotor memory that accompanies writing. The practical implication is that an integration of character handwriting and Pinyin typing promotes learning to read Chinese in a second language learning context.
\end{abstract}

Keywords: handwriting, phonology, integration, cognitive tutor, Chinese learning

Skilled reading depends in part on word-specific representations that are accessed through written word forms. When a representation includes well-specified and interconnected orthographic, phonological, and semantic constituents, it is said to be high in lexical quality (Perfetti, 2007). Lexical representations, according to the lexical quality hypothesis (Perfetti \& Hart, 2002; Perfetti, 2007), can affect comprehension through the ease of word identification and the retrieval of word meanings required by the context of the text. For example, a fully specified (high quality) representation of a word's orthography should lead to more rapid word

This article was published Online First July 18, 2011.

Connie Qun Guan, School of Foreign Languages, East China Normal University, Shanghai, China, and Department of Psychology, Florida State University; Ying Liu, Department of Psychology, LiaoNing Normal University, Dalian, China; Derek Ho Leung Chan, Feifei Ye, and Charles A. Perfetti, Learning, Research, \& Development Center, University of Pittsburgh.

Funding for this research was provided by National Science Foundation Grant SBE-0836012 to the Pittsburgh Science of Learning Center (PSLC, http://www.learnlab.org). We are indebted to PSLC CTAT technicians for programming the tutor. We are also grateful for helpful comments from Agnes Au and Renlai Zhou concerning earlier versions of this article.

Correspondence concerning this article should be addressed to Connie Qun Guan, School of Foreign Languages, East China Normal University, Shanghai, Peoples Republic of China 200062 or to Charles Perfetti, Learning, Research, \& Development Center, University of Pittsburgh, 3939 O'Hara Street, Pittsburgh, PA 15260. E-mail: conniequnguan@gmail.com or perfetti@pitt.edu identification than a partially specified orthography. Although lexical quality can improve through reading and writing practice, specific instruction in word forms (e.g., spelling) and word meanings (e.g., vocabulary knowledge) can also be important. Here, we examine the orthographic constituent of lexical knowledge and examine how it can be strengthened through instruction. Our examination brings into focus the role that a writing system, for example, alphabetic versus Chinese, plays in defining the orthographic constituents of words and in defining how they link to other lexical constituents.

In alphabetic reading, orthographic knowledge is intimately tied to the phonological constituent of a word, and thus, strengthening the phonological representations of words is a critical component of learning to read (Rayner, Foorman, Perfetti, Pesetsky, \& Seidenberg, 2001; Vellutino, Fletcher, Snowling, \& Scanlon, 2004; Ziegler \& Goswami, 2005). This does not mean that strengthening the word-specific orthographic representations is not important in English and other alphabetic writings. In fact, phonological decoding may support the establishment of word-specific orthographic representations in alphabetic writing (Share, 1995). Beyond this "bootstrapping" by phonology, more practice at reading serves to make orthographic forms more familiar and thus more accessible for reading. Beyond reading experience, writing of words can further refine and provide further practice at orthographic forms (Bowers, Davis, \& Hanley, 2005; Ricketts, Bishop, \& Nation, 2009). A growing body of research has explored writing over the past few years, but the effects of writing have been found to be 
inconsistent and, on average, small (Bi, Han, \& Zhang, 2009; Caramazza \& Mahon, 2006; Packard et al., 2006; Tan, Spinks, Eden, Perfetti, \& Siok, 2005). It is known that alphabetic writing functions through sublexical structures built on a small set of orthographic units (letters) that are mapped to phonemes and productively recombined to form written words. Given this fact, it is possible that writing-on-reading effects in alphabetic systems are less robust and thus less consistently observed. This implies that writing may produce only modest gains on orthographic representations.

\section{Writing in Chinese Reading}

Writing could be especially important in the case of the logographic writing system of Chinese, whose basic writing units do not correspond to phonemes but map onto syllable-morphemes (e.g., DeFrancis, 1989; W. S.-Y. Wang, 1973; Yin \& Rohsenow, 1994). Orthographic representations of Chinese lexemes (i.e., characters) tend to be word-specific, with little or no systematic phonology. This fact places a burden on developing precise representations of visual-orthographic forms in order to acquire a written vocabulary of 7,000 basic characters (Chinese Language Committee, 2009). The Chinese character consists of any or all of eight basic strokes interwoven in patterns to form component radical(s) in a two-dimensional square. Writing characters involves the coupling of writing related visual and motor systems. This coupling may help establish the spatial configuration of strokes and radicals, which along with a temporal sequence of motor movements associated with stroke composition, completely defines the shape of the character.

Although the character form itself is the immediate locus of this effect, the character form is linked with two other constituents, phonology and meaning. For highly skilled readers, in the lexical constituency model (Perfetti \& Tan, 1998; Perfetti, Liu, \& Tan, 2005), it is assumed that parallel pathways from orthography to meaning and orthography to phonology converge at the moment of word identification. Although timing asynchronies between phonological and semantic activation can occur in both directions, successful word identification depends on the rapid integration of all three types of information. The ability of the character form to drive this identification process depends on the quality of its representation and its connections to meaning and phonology.

The application of this model of highly skilled reading to the low skill of the second language learner would need to accommodate massive asynchronies among the constituents. The three constituents may not be equally well learned, with variability resulting from the relative emphasis that instruction places on spoken and written processes. Without an emphasis on spoken language in second language learning, writing may especially strengthen the link from orthography to meaning.

\section{Evidence for Writing Effects in Chinese}

Evidence for writing effects in Chinese reading is set in a literacy context that supports a strong connection between reading and writing. Chinese children learn character reading with character writing in early literacy instruction. They are taught the appropriate stroke sequences for individual characters, which become motor programs (allographs) in memory with repeated writ- ing practice. Once the motor memory has been learned and stabilized, it can last for very long periods of time. For example behavioral studies indicate that sensory-motor memory traces, inferable from stroke sequences in partial character primes, facilitate character recognition (Flores d'Arcais, 1994). Recently, correlational studies have also established writing-reading connections. Tan et al. (2005) examined Chinese children's writing and copying skills among normal readers in a Beijing primary school and concluded that skilled reading is highly correlated with the ability to copy characters. Chan, Ho, Tsang, Lee, and Chung (2006) also found a similar substantial correlation between reading and writing in Chinese children with dyslexia in Hong Kong. Furthermore, some functional brain-imaging studies have found that judging visual words involves brain areas that may be associated also with writing (Siok, Niu, Jin, Perfetti, \& Tan, 2008). Taken together, accumulating and consistent behavioral, anatomical, and functional imaging research tends to support the hypothesis that writing experience contributes to reading skill in Chinese literacy (Tan et al., 2005; Siok et al., 2008).

The correlational nature of these studies, however, does not allow the conclusion that writing plays a causal role in reading development (Caramazza \& Mahon, 2006). As Packard et al. (2006) observed, reading and writing might be associated without having a causal relationship, instead linked through some third variable, such as cognitive ability (e.g., orthographic knowledge, phonological memory, etc.), which affects both skills independently. Bi et al. (2009) described a patient with severe writing impairment and poor orthographic awareness who could nonetheless match characters to meaning-related pictures and read them aloud. This case might be taken to demonstrate that whatever supportive role writing might play in Chinese reading, it is not a necessary condition for learning to read.

\section{Research Context and Hypotheses}

Our experiment tests the hypothesis that writing supports reading in the context of adult second language learning, in which, in contrast to children's native language (L1) literacy in Chinese, the role of writing has not been examined. The rationale for a writing effect includes the basic writing system facts we reviewed above and the consequences they hold for establishing orthographic representations. The orthographic representations that are critical for reading are unique for each character and thus place a burden on memory for orthographic forms (Perfetti et al., 2005; Taft, Zhu, Peng, 1999). This burden may be especially significant for adult learners of Chinese as a second language (L2). L1 beginning readers acquire orthographic representations for words that are already in their spoken language vocabulary. Adult L2 learners are acquiring spoken language at the same time they are learning to read. Thus, the words they are learning to read may be unfamiliar not only as written forms but also as spoken words. Under such circumstances, writing may support the learning of the unfamiliar orthographic form by linking it to meaning translations in L1. Indeed, for L2 learners of Chinese in college classrooms, the meaning of characters is likely to be learned prior to their form, unless spoken language is strongly emphasized in the classroom (M. Wang, Perfetti, Liu, 2003).

The context for the two studies we report includes the Pittsburgh Science of Learning Center (PSLC) and its LearnLab infra- 
structure. The studies test the general hypothesis that knowledge components are made more robust by instructional events that promote the integration of components across modalities (see http://www.learnlab.org/). In Experiment 1, we examined whether and to what extent adult beginning learners of Chinese could take advantage of the addition of character writing to character reading. In Experiment 2, we examined whether and to what extent the method of integrating character writing with Pinyin-typing (to support phonological representations) could strengthen the associated links among a word's graphic, phonological, and semantic constituents.

\section{Experiment 1}

Experiment 1 was designed to examine the learning pattern of Chinese lexical constituents when characters were introduced through reading plus handwriting (the handwriting condition), compared with reading only (the reading-only condition). We assessed learning of the orthographic form and its links to meaning and pronunciation.

\section{Method}

Participants. Thirty Carnegie Mellon University students, aged 18-26 years and enrolled in Elementary Chinese II, received $\$ 40$ for their participation in the 4-hr experiment. The ethnic makeup of the participants was $13.8 \%$ (4) Caucasian and $86.2 \%$ (25) Asian. Among the students of Asian heritage, 56\% (14) were Korean, 28\% (7) were Chinese, 8\% (2) were Japanese, and 8\% (2) were from other ethnic backgrounds. Nearly all of the participants (96.6\%) had some experience in Chinese-character writing before their participation in this experiment. At the point of this current experiment, $57.2 \%$ had learned Chinese for less than half a year, $21.4 \%$ had learned Chinese for about 1 year, and $21.4 \%$ had learned Chinese for less than 2 years; $71.4 \%$ of them could read about $50-100$ characters, and $28.6 \%$ could read $100-150$ characters.

Materials and procedures.

Characters selection. A total of 54 traditional Chinese characters were selected to be used in Experiment 1 (see Appendix 1). They were from Lessons 14-23 in the curriculum of Elementary Chinese II (Wu, Yu, Zhang, \& Tian, 2005). Their radicals had not been introduced in class at the time this experiment was conducted, and they were all compound traditional characters in any of the three orthographic configurations: top-down, left-right, and outside-inside. These characters were put into three groups matched by their orthographic configuration, stroke number, number of radicals, and English-translation frequency (Kučera \& Francis, 1967). One out of each matched set was randomly selected for each condition. The first group of characters was presented in the reading-only condition, and the second group was presented in the handwriting condition. The third group was not taught but was used for test purposes as novel control stimuli. There were no homophones in the selected characters. The 36 characters, 18 in each of the two learning conditions, were taught over 3 different days: six characters per condition were taught on Day 1, the other 12 characters per condition were taught on Day 2, and all 18 characters in each of the two conditions were taught again on Day 3 , thus allowing each character two learning trials over the 3 days.
All the visual and audio files of those characters were accessed from a server dedicated to this experiment.

Procedure. We conducted a pilot to determine the number of exposures that students needed to read a character and the time required in writing the character from memory. This led to the following trial parameters: A total time of $60 \mathrm{~s}$ for each learning trial, consisting of 3 separate 4-s exposures of the display plus $15 \mathrm{~s}$ per exposure for writing. (One second estimated time was needed for character uploading at each display.) The 4-s display began with the presentation of the character image, viewable for the entire $4 \mathrm{~s}$; an audio file of the character's pronunciation, $1 \mathrm{~s}$ after the onset of the display; and the English translation of the character, viewable for $1 \mathrm{~s}$ following the offset of the pronunciation. This display was identical for two conditions.

The two conditions varied only in what followed the offset of the 4-s display. In the reading-only condition, participants were told to mentally recall the character they had just viewed. In the handwriting condition, they were told to try to write the character from memory. Exposure time was controlled so that following the initial 4-s display, $45 \mathrm{~s}$ were allotted for study time. During that period, the student could reinitiate the display two additional times, with a study time of $15 \mathrm{~s}$ each, for a total of three exposures. Each exposure was a complete replication of the display events (character, spoken syllable, translation). Thus, the trial time for each character was $60 \mathrm{~s}$ (including 1-s character upload time for each display), distributed among up to three display exposures and study time. Examples of the interfaces of the two learning conditions are shown in Figure 1. The sound icon indicates the audio file that was played automatically $1 \mathrm{~s}$ after the onset of the image of character. Time on task was recorded as the number of seconds each participant spent on either writing or recalling the character during the $60 \mathrm{~s}$ trial. There was no statistical difference in time on task between the two learning conditions, $t(29)=-0.37, p=$ .791 .

Instrumentation. The tutor was linked to a file server that contained all the audio files of the characters' pronunciation and image files of characters' form and English translation. The writing was enabled by a cyber-pad pointing device (Addesso 3.0) positioned adjacent to the computer keyboard. The writing produced by the input device was made visible in a writing box on the right-hand side of the computer screen. The learning interfaces were designed with Java codes that were aligned with the tool development provided by the Cognitive Tutor Authorizing Tool (CTAT; http://ctat.pact.cs.cmu.edu/). We used CTAT's ExampleTracing Tutor to support the two experimental scenarios described above, including detailed logging of student-tutor interactions and $\log$ analysis (Aleven, McLaren, Sewall, \& Koedinger, 2009).

We assessed participants' orthographic form knowledge through a lexical decision task and constituent knowledge through English meaning and pronunciation (including Pinyin segment and tone) tasks in both the pretest and the posttest. A partial cue-based recognition task was aimed at testing the effect of stroke order on character recognition. The detailed implementation of each of these tests is below.

Pretest. Although characters were selected to be beyond the students' curriculum range, we assessed students' knowledge of the characters on the first day, prior to the training session. In this pretest, participants proceeded at their own pace through all the characters. All participants got the same random order within a 

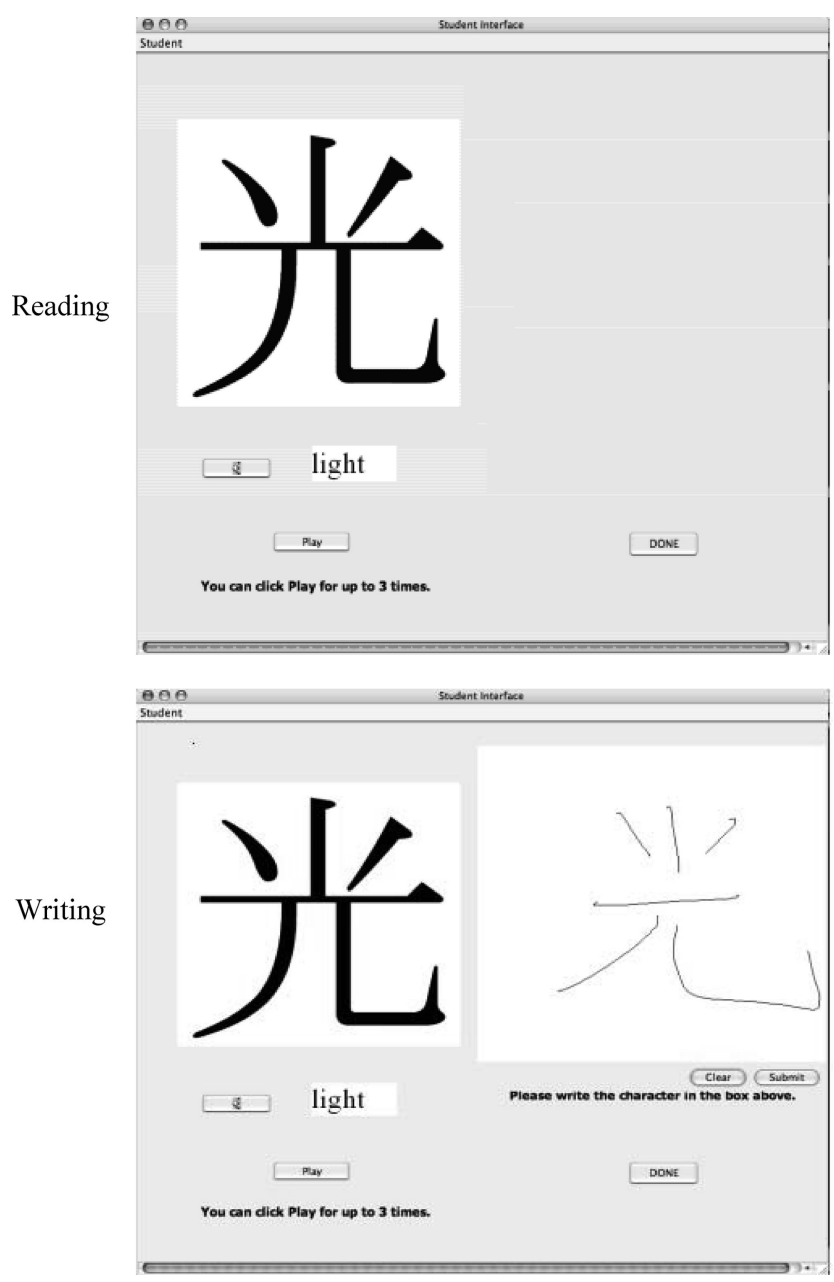

Figure 1. The interfaces of two learning conditions in Experiment 1.

condition. They responded to each character shown on the screen by typing its Pinyin, including tone and English meaning. If no response was produced within $40 \mathrm{~s}$, the trial was ended by the appearance of the next character. Participants knew very few of the chosen characters: accuracy rates for Pinyin, tone, and English meaning were $13 \%, 9 \%$, and $12 \%$, respectively, for those characters that would appear in the reading only condition, and $11 \%, 6 \%$, and $9 \%$, respectively, for those characters that would appear in the handwriting condition. These differences were not significant between conditions but were taken into consideration in the final analyses.

Posttest. To assess the learning gains for the characters taught during the training session, each day's session ended with a posttest. Participants proceeded once through all the characters taught that day, responding in the same fashion as in the pretest. Six taught characters per condition were assessed on Day 1, the other 12 taught characters per condition were assessed on Day 2, and all 18 characters in either of the two conditions were taught and assessed on Day 3. The analyses were only based on Day 3's posttest scores.

Lexical decision task. Participants decided whether the stimulus shown on a computer screen was a real character. This was our primary recognition test, one assumed to be sensitive to the visual-orthographic representations that were the focus of training. The task included a mixture of 72 real characters and 72 noncharacters. The real characters included 36 taught characters, 18 novel characters, and another 18 familiar characters selected from the elementary Chinese curriculum that had been introduced to the students by the time of the training session. The 72 noncharacters included two groups: legal radicals in illegal positions or illegal radicals constructed by adding, deleting, or moving a stroke from one location to another within a legal radical. The examples of real characters are 離, 甜, 鼓, and 病. The examples of noncharacters are 隹离(legal radicals in illegal positions), 甜(deleting a stroke), 鼓 (adding a stroke), and 病 (moving a stroke).

Partial cue-based character recognition task. This task required participants to decide whether the first of two consecutively presented character images (a partial character missing the early, middle, or late strokes) was contained in the second image (a whole character). The rationale for this task was that if writing mediates character recognition, then previewing the first-made strokes would lead to better character recognition than previewing last made strokes (Flores d'Arcais, 1994). In this task, participants were instructed to respond by pressing yes if the first image was part of the complete second image and no otherwise (see Figure 2 for sample stimuli). One third of the partial characters lacked strokes from the beginning of the stroke sequence (e.g., 析-新, xin1, new), one third lacked strokes in the middle (e.g., 盘 - 盤, pan2, plate), and one third had strokes removed from the final position (e.g., 咸- 感, gan3, feel) of the character image. There were 72 image pairs in total, 36 (12 each of beginning, middle, and late sequences) matching (yes response) and 36 mismatching (no response). To require that the decision be made on the basis of orthography rather than only visual form, the font of the two images in each pair differed from each other. The participants' accuracy rates for each image pair were recorded.

Training and testing schedule. The experiment was carried out on 3 separate days over a period of less than 2 weeks. The procedure and its implementation flowchart are shown in Figure 3. The character constituent knowledge tests (i.e., pre- and posttest on Pinyin segment, tone, and English meaning) were administered immediately before training and after the training on Days 1, 2, and 3. The lexical decision and partial-cue-based character recognition tasks were given at the end of Day 3. All tasks were computerized. The pretest and posttest were implemented by the CTAT program. The lexical decision and partial-cue-based character recognition tasks were run with E-prime 2.0.

\begin{tabular}{|c|c|c|}
\hline First Image & Second Image & Response \\
\hline 䄬 & 新 & Yes \\
\hline 盘 & 盤 & Yes \\
\hline 咸 & 感 & Yes \\
\hline 常 & 賞 & No \\
\hline
\end{tabular}

Figure 2. Sample stimuli in the partial cue-based character recognition task. 


\begin{tabular}{|c|c|c|}
\hline $\begin{array}{l}\quad \text { Day 1 } \\
\text { 1. Demographic Questionnaire } \\
\text { 2. Pretest } \\
\text { (12 new Characters) } \\
\text { 3. Training Session } \\
\text { Reading condition } \\
\text { (6 Characters) } \\
\text { Handwriting condition } \\
\text { (6 Characters) } \\
\text { 4. Posttest } \\
\text { (12 learned characters) }\end{array}$ & $\begin{array}{l}\quad \text { Day } 2 \\
\text { 1.Pretest } \\
\text { (24 new characters) } \\
\text { 2. Training Session } \\
\text { Reading condition } \\
\text { (12 Characters) } \\
\text { Handwriting condition } \\
\text { (12 Characters) } \\
\text { 3. Posttest } \\
\text { ( } 24 \text { learned characters) }\end{array}$ & $\begin{array}{l}\text { Day } 3 \\
\text { 1. Training Session } \\
\text { Reading condition } \\
\text { (18 characters) } \\
\text { Handwriting condition } \\
\text { (18 characters) } \\
\text { 2. Posttest } \\
\text { ( } 36 \text { learnedcharacters) } \\
\text { 3. Lexical decision task } \\
\text { 4. Partial-cued based } \\
\text { recognition task }\end{array}$ \\
\hline
\end{tabular}

Figure 3. Design flowchart used in Experiment 1.

Design. A $2 \times 2$ mixed analysis of variance (ANOVA) tested learning condition as a within-participant factor and presentation order as a between-participants factor. Two presentation orders were implemented: reading $\rightarrow$ handwriting and handwriting $\rightarrow$ reading. Half of the participants received the first presentation order, and the other half received the second presentation order. The selection of participants to each presentation order was random.

Analyses. Because the participants were learners rather than skilled readers of Chinese, we expected accuracy of lexical decision to be sensitive to learning. Accuracy was also the dependent variable on the partial recognition task. To test the effect of condition on the learning of meaning and pronunciation, the dependent variables included (a) the accuracy rates for English meaning, Pinyin segment transcription, and tone and (b) the accuracy of students' meaning and Pinyin segment recall of the tested items. Both analyses had the same independent variables: learning condition and presentation order. The preliminary analyses showed no order effect $(p s>.05)$, so its effect was not reported or discussed in the next section.

\section{Results}

The results for the immediate posttest and character-form recognition tasks are displayed in Table 1 . The percentages of correct responses reveal a consistent learning effect, with the handwriting condition more effective than the reading condition. As expected, there was a handwriting effect on the retrieval of English meaning, with stronger word form-meaning association in the handwriting condition than in the reading condition, and on the orthographic knowledge tests, with the handwriting condition producing higher proportions of accurate responses on both the lexical decision task and the partial-cue-based recognition task.

Handwriting effect on orthographic recognition. For lexical decisions, our main measure of orthographic recognition, the handwriting condition led to better performance (proportion correct $=.80$ ) than the reading only condition (proportion correct $=$ .57). The reliability of this large difference was confirmed with an ANOVA with learning condition as a within-participant factor: a main effect of learning condition, $F(1,28)=29.02, M S E=0.812$, $p<.001, \eta^{2}=.34$. For novel characters, which can be considered

Table 1

Proportion of Correct Responses for All Learning Measures Between Conditions in Experiment 1

\begin{tabular}{|c|c|c|c|c|c|}
\hline \multirow[b]{3}{*}{ Tasks } & \multicolumn{4}{|c|}{ Learning conditions } & \multirow[b]{3}{*}{ Cohen's $d$} \\
\hline & \multicolumn{2}{|c|}{ Reading } & \multicolumn{2}{|c|}{ Writing } & \\
\hline & Proportion & Variance & Proportion & Variance & \\
\hline \multicolumn{6}{|l|}{ Pretest sessions } \\
\hline Meaning-translation & .12 & .09 & .09 & .08 & \\
\hline Pinyin segment & .13 & .13 & .11 & .14 & \\
\hline Tone & .09 & .11 & .06 & .09 & \\
\hline \multicolumn{6}{|l|}{ Posttest } \\
\hline Meaning-translation & .42 & .25 & .45 & .23 & \\
\hline Pinyin segment & .30 & .25 & .34 & .23 & \\
\hline Tone & .23 & .20 & .25 & .19 & \\
\hline \multicolumn{6}{|l|}{ Pretest vs. posttest gains } \\
\hline Meaning-translation & .30 & .22 & .36 & .19 & $0.97^{\mathrm{a}}$ \\
\hline Pinyin segment & .17 & .18 & .22 & .19 & 0.29 \\
\hline Tone & .14 & .15 & .19 & .18 & 0.29 \\
\hline \multicolumn{6}{|l|}{ Form-recognition test } \\
\hline Lexical decision & .57 & .18 & .80 & .17 & $1.44^{\mathrm{a}}$ \\
\hline Partial recognition & .87 & .11 & .91 & .07 & $0.91^{\mathrm{a}}$ \\
\hline \multicolumn{6}{|l|}{ Transfer novel characters } \\
\hline Lexical decision & .56 & .16 & .61 & .16 & $0.59^{\mathrm{a}}$ \\
\hline
\end{tabular}

${ }^{a}$ Indicates that the strength of the association was statistically significant. We calculate Cohen's $\mathrm{d}$ by using the following formula: $\left[4 \eta^{2} / 1-\eta^{2}\right]^{1 / 2}$. 
to test transfer of learning, there was a tendency for higher accuracy in the handwriting condition (.61) than in the reading only condition (.56), $F(1,28)=4.84, M S E=0.022, p=.03, \eta^{2}=.08$.

Similarly, in the partial cue-based recognition task, participants made more correct judgments on the target characters taught in the handwriting condition (accuracy $=.91$ ) than in the reading only condition (accuracy $=.87$ ); there also was a reliable difference, $F(1,28)=11.28, M S E=0.091, p=.001, \eta^{2}=.17$.

Writing effect on orthography-semantics and orthographyphonology links. Handwriting led to a higher gain from pretest to posttest in the meaning task (.36) than did reading only (.30), $F(1,58)=12.7, M S E=138.618, p=.001, \eta^{2}=.19$. However, the gains in the Pinyin task from pretest to posttest were smaller and not different between the two conditions. For Pinyin segments, the gains were .17 and .23 for reading only and writing, respectively. For tone, the gains were .14 for reading and .19 for writing. Although both gains were higher for writing than for reading, these differences were not reliable $(F \mathrm{~s}<1)$.

\section{Discussion}

This pattern of results highlights two points. First, for both tasks of word-form recognition, the performance in the handwriting condition was consistently better than that in the reading only condition. Our interpretation is that when characters are taught with handwriting, the characters (including their constituent radicals) become represented in a higher quality form. This higher quality representation then allows for better recognition at a later point. Behavioral studies had indicated this potential for the effect of handwriting on reading by showing effects of writing on memory (Longcamp et al., 2008; Longcamp, Zerbato-Poudou, \& Velay, 2008; Flores d'Arcais, 1994) and mental imagery (Kosslyn, Cave, Provost, \& Van Gierke, 1988) of characters. Whereas this previous research used arbitrary symbols rather than real written language, the present experiment demonstrates the effect of writing on reading when students are attempting to learn Chinese characters as part of a course. Second, the performance gains in meaning translation for the handwriting condition demonstrate that the enhanced gain in form knowledge supports connections from form to other lexical constituents, at least the form-meaning connection in the case of this experiment. This means that the effect of writing is on reading, not just inert form knowledge.

The source of the writing effect may be that writing establishes a visual-spatial or perceptual-motor memory of the strokes made to write the character. These memory traces would be activated when the reader views the character, perhaps instantiating information about stroke sequence and other perceptual-motor components of writing. A second alternative makes no appeal to a supplementary perceptual motor representation but simply emphasizes the greater attention directed to the form of the character by the task of writing. That is, because the learner knows during the brief viewing of the character that writing will be required at the offset of the character, attention is engaged by the form of the character while it is viewable.

This causal issue is the subject of a recent neuroimaging study by Cao et al. (2010) with a comparable college population. Using functional magnetic resonance imaging (fMRI) to study brain activation patterns after handwriting training, they found that compared with a Pinyin writing control condition, characters trained with writing produce more activation in brain areas associated with visual spatial processing, motor activity, and semantic processing. Although they do not rule out the possibility that visual attention, not writing per se, is the mechanism that causes the writing effect, it shows that the brain's reading network for Chinese is enhanced through writing.

A remaining question concerns the learning of pronunciation, as evidenced by Pinyin spelling. Pronunciation was not as well learned as meaning through either condition. Although writing produced gains that were larger than for reading only, these differences were not reliable statistically. Thus, one wonders not only whether writing can enhance the phonology link as well as the meaning link but also what learning procedures might increase the level of phonological knowledge generally. Because the mapping of Chinese writing to pronunciation is opaque relative to alphabetic writing, learning the phonological mapping of characters is more difficult. An additional obstacle is the intrinsic phonological differences (especially tone) between Chinese and other languages that were native to our learners. We reasoned that an integrative approach to character learning, that is, one that aims at the phonology links as well as the semantic links, could strengthen the orthography-meaning link through writing while strengthening the orthography-phonology link through Pinyin typing. In Experiment 2, we implemented this idea, creating conditions of Pinyin typing as well as character writing as support for learning.

\section{Experiment 2}

Our goal in Experiment 2 was threefold. First, we aimed to learn whether coding pronunciations in Pinyin spelling (through typing) could help learners acquire a stronger phonological representation. Second, we aimed to learn whether a combination of character handwriting and Pinyin typing would strengthen the connections among all word constituents - character, pronunciation, and meaning. Finally, by having participants engage in Pinyin typing during learning, we create a general control for the motor activity that is part of the writing condition.

Pinyin is an alphabetic script used in Mainland China, first introduced to all 6-year-old children in the People's Republic of China in the 1950s. Similar to Zhu-Yin-Fu-Hao in Taiwan, Pinyin helps children map print to their spoken word knowledge. When the Pinyin is presented with characters as they are first introduced, characters can be read correctly. Pinyin letters plus tone markers map 21 onsets, 35 rimes, and 4 lexical-tone representations of spoken Mandarin (Institute of Linguistics, Chinese Academy of Social Sciences, 2004). For example, the Pinyin of character 设 shown in Figure 2 is she4, with sh representing its unique individual onset, $e$ representing the rime, and 4 as a falling tone.

Thus, the value of Pinyin is that it supports the functioning of phonological links during reading, which is a highly general characteristic of skilled reading. The universal phonological principle (Perfetti, Zhang, Berent, 1992; Perfetti \& Tan, 1998) postulates a generalizable word reading mechanism that engages phonology in recognizing printed words across all writing systems. In Chinese, the character becomes linked to phonology, a spoken syllable morpheme. Pinyin (also Taiwan's Zhu-Yin-Fu-Hao) provides an early link to phonology during beginning reading instruction and promotes Chinese word reading. For example, Pinyin helps adult (Fredlein \& Fredlein, 1994) and adolescent (Huang \& Hanley, 
1997) Chinese speakers to identify unfamiliar characters. Even preschoolers' invented Pinyin spelling is a longitudinal predictor of later Chinese word reading (Lin et al., 2010). More generally, for adults as wells a children, Pinyin provides a coding system that can retrieve the phonological memory of a syllable (Leong, 1997; Ziegler et al., 2010).

Learners of Chinese in the United States often begin to learn some spoken language with the support of Pinyin before they undertake reading and writing tasks, although the efficacy of this approach has been little studied. Our assumption is that for Chinese L2 learners, Pinyin functions to support the acquisition of a phonological representation. When instruction emphasizes spoken language, this representation is the spoken language form, and the Pinyin helps retrieve that spoken form. When instruction emphasizes written language more than spoken, the phonological representation is more a decoding of Pinyin spelling than a phonetically precise spoken language form. Its value then would be as a distinctive cue (an associated pronunciation) for the character in addition to its meaning.

In Experiment 2, we designed a Pinyin-typing tutor to add to our handwriting tutor. The key rationale is the assumption concerning the alphabetic coding of spoken words. This assumption is that writing Pinyin in response to a recently heard word helps stabilize the phonological representation of the word. In turn, this more robust representation is more available for linking to other constituents, graphic form, and meaning. Our primary aim was to test the hypothesis that alphabetic coding through Pinyin typing would facilitate character-to-pronunciation learning. A secondary aim was to test the hypothesis that following Pinyin training with writing training would facilitate the integration of lexical constituents. That is, links among character form, meaning, and pronunciation would all be strengthened. Finally, Experiment 2 provides a within-experiment control for learner activity during training. Whereas in Experiment 1 we compared writing with more passive reading only, in Experiment 2, we included a comparison of two conditions that each engaged the learner in active processing, including motor activity, during training.

\section{Method}

Participants. A new group of 37 Carnegie Mellon University students, aged 17 years to 35 years and enrolled in Elementary Chinese II, received $\$ 40$ for their participation. The ethnic makeup of the participants was 27\% (10) Caucasian and 63\% (27) Asian. Among the students of Asian heritage, $70.4 \%$ (19) were Korean, $14.8 \%$ (4) were Chinese, $7.4 \%$ (2) were Japanese, and $7.4 \%$ (2) were from other ethnic backgrounds. Their Chinese proficiency was at the same level as those in Experiment 1. Nearly all of the participants $(96.7 \%)$ had some experience in Chinese-character writing before their participation in this experiment. At the point of this current experiment, $67.5 \%$ had learned Chinese for less than half a year, $16.2 \%$ had learned Chinese for about 1 year, and $16.3 \%$ had learned Chinese for less than 2 years; $70.2 \%$ of them could read about 50-100 characters, and $29.8 \%$ could read $100-$ 150 characters.

Design. A between-subjects design produced random selection of participants for one of two groups. Group WW (writing + writing; $n=18$ ) received writing training on both Day 1 and Day
2. Group PYW (Pinyin + writing; $n=19$ ) received the Pinyintyping training on Day 1 and the writing training on Day 2.

Materials and procedures.

Character selection. The experimental materials contained the same 36 characters used in Experiment 1 plus 4 new characters. These 40 characters were used in both conditions described below.

Procedure. Display parameters were identical to Experiment 1 and were the same for both conditions. The handwriting condition was the same as that in Experiment 1. In the Pinyin-typing condition, following the offset of the 4-s form-sound-meaning display for each character, participants were required to type the Pinyin (including onset and rime) and tone ( $1=$ high level, $2=$ rising, 3 = falling-rising, and 4 = falling) associated with a character. They had three attempts to do so and only a "correct" or "incorrect" feedback was given after each attempt. Because there were no homophones in our selected character list, only one character could be matched. After the third attempt, the target character flashed for just $1 \mathrm{~s}$, and then the learning interface advanced to the next character, regardless of whether the participant had correctly typed the Pinyin and tone of the character. In both learning conditions, participants were instructed to associate the link of each character with its pronunciation and meaning. As in Experiment 1, the trial for each character allowed a total of $60 \mathrm{~s}$. The two major interfaces of the learning conditions are shown in Figure 4. Time on task was recorded as the number of seconds spent on either writing the character or typing the Pinyin of the character over the $60 \mathrm{~s}$ trial. These times did not differ between the two conditions, $t(35)=0.26, p=.763$.

Pretest and posttest. Pretest and posttest on English meaning, Pinyin segments, and tone were identical to those used in Experiment 1. The purpose of the pretest was to determine the degree of initial familiarity with the characters in the experimental conditions (i.e., either Pinyin-typing or character writing). Statistical tests of the pretest scores confirmed that the two groups did not differ. The posttest required the participants to produce the English meaning, Pinyin segment (onset and rime), and tone for each character.

Lexical decision task and partial cue-based recognition task. As in Experiment 1, these two tasks served as orthographic recognition measures.

Pinyin dictation. In this task, participants heard a spoken syllable that had been associated with a character during training. They had up to three attempts to provide both its Pinyin segment and tone, with a correct or an incorrect feedback after each of the first two attempts. They received an auditory input before each attempt. No feedback was given after the third attempt.

Meaning task. Following the Pinyin dictation task, participants viewed characters one at a time and provided their English meaning. No feedback was given.

Training and testing schedule. Experimental procedures were conducted on 3 separate days within a 2-consecutive-week period. (See the design flowchart in Figure 5.) Day 1 and Day 2 began with tests and proceeded with training. On Day 1, participants were given the pretest on Pinyin segment and tone and English meaning of all 60 characters. Day 2 and 3 tests included the pretest, the lexical decision task, the partial-cue-based character recognition task, and the Pinyin dictation task.

Analyses. All the dependent measures, which included lexical decision, partial recognition, auditory Pinyin recognition, auditory English translation, posttest of English translation, and 

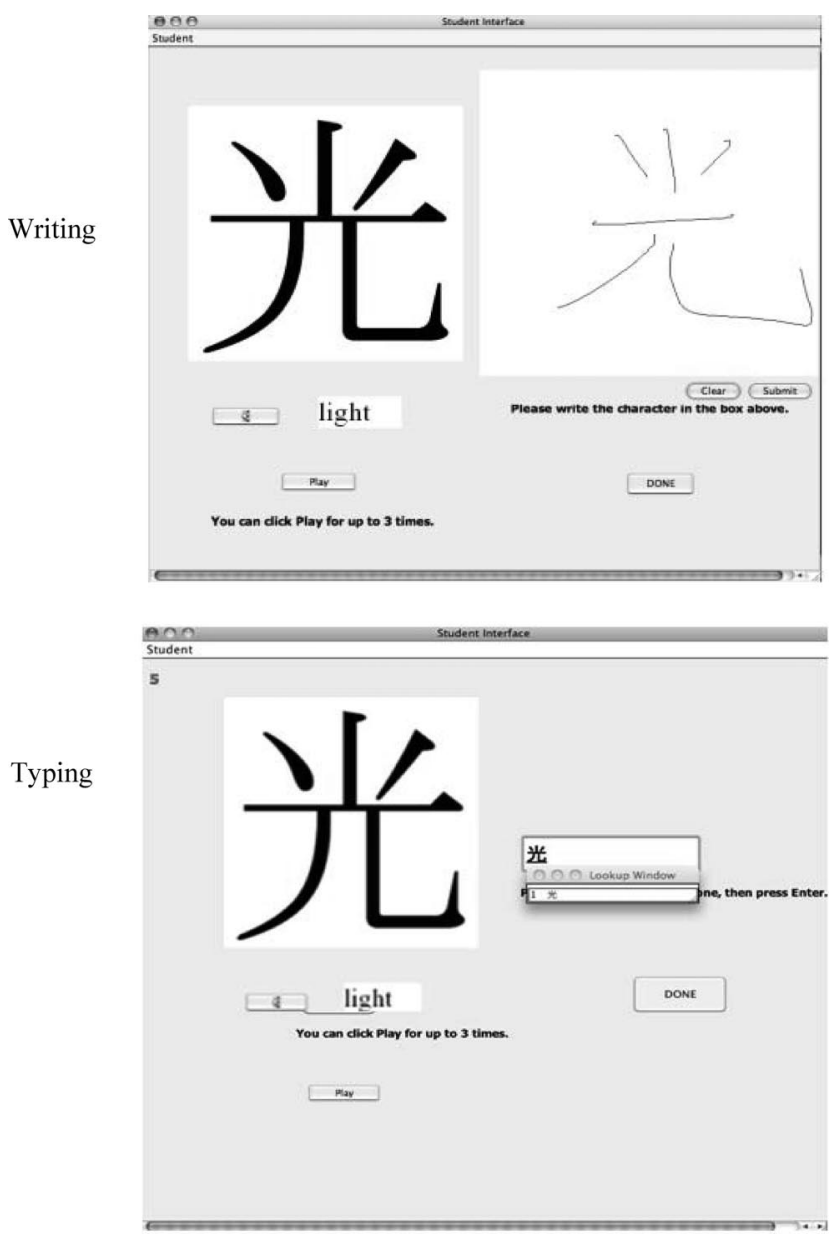

Figure 4. The interfaces of two learning conditions in Experiment 2. Presentation order of all items was randomized.

posttests of Pinyin segment and tone, were scored based on the proportion of accurate responses. There was no statistical difference between the two groups on any of these variables on Day 1's pretest. Four separate one-way ANOVAs were conducted to directly address the specific contrast we planned to examine, that is, the effect of handwriting, the effect of phonology, the effect of two-way handwriting, and the effect of a 1-day integrative ap- proach of handwriting and phonology. Results of these analyses were reported the discussed next.

\section{Results}

The descriptive statistics for all dependent measures for the two groups of participants are displayed in Table 2.

As evidenced in Table 2, the percentages of correct responses reveal a consistent handwriting effect, with group WW (writing + writing) performing better on orthographic recognition and orthography-semantic mapping tasks than group PYW (Pinyin + writing). These results replicate the writing effect of Experiment 1 relative to an active control condition. As predicted, there was also a Pinyin-typing effect on the phonological identification task after the first day's training. Most interesting, group PYW benefited from the integrative approach on both phonology-semantic mapping and orthography-phonology mapping tasks. The following paragraphs report these results in detail. Because the characters selected for training were exactly the same in the two groups and because there were no character-level research questions, all the analyses were conducted on the participant level.

Handwriting effect on orthographic recognition. The first question is the direct comparison of writing with Pinyin typing that is possible at the end of Day 1. For lexical decisions, our main measure of orthographic recognition, the handwriting condition led to better performance (proportion correct $=.52$ ) than the Pinyintyping condition (.43), $F(1,35)=8.388, M S E=0.725, p=.005$, $\eta^{2}=.07$, after Day 1 training. After the handwriting training on Day 2, the performance of both groups on this task improved significantly from Day 1: for the WW group, $F(1,17)=14.351$, $M S E=0.849, p<.001, \eta^{2}=.204$; for the PYW group, $F(1$, $18)=4.921, M S E=0.811, p=.03, \eta^{2}=.15$. The gains from Day 1 to Day 2 were comparable across groups: .10 and .12 for group WW and group PYW, respectively. Unlike the results for Day 1, the Day 2 difference in performance between the two groups was not reliable, $F(1,35)=1.45, M S E=0.02, p=.23$, $\eta^{2}=.01$

Similarly, in the partial-cue-based recognition task, despite being near ceiling overall, group WW could more accurately judge partial images of characters as parts of their corresponding targets (.98) than group PYW (.94), $F(1,35)=5.698, M S E=1.426, p=$ $.019, \eta^{2}=.05$, after Day 1 training. This high level of accuracy limited the opportunity for significant improvement on Day 2, when their mean proportion correct was .99. For group PYW, there

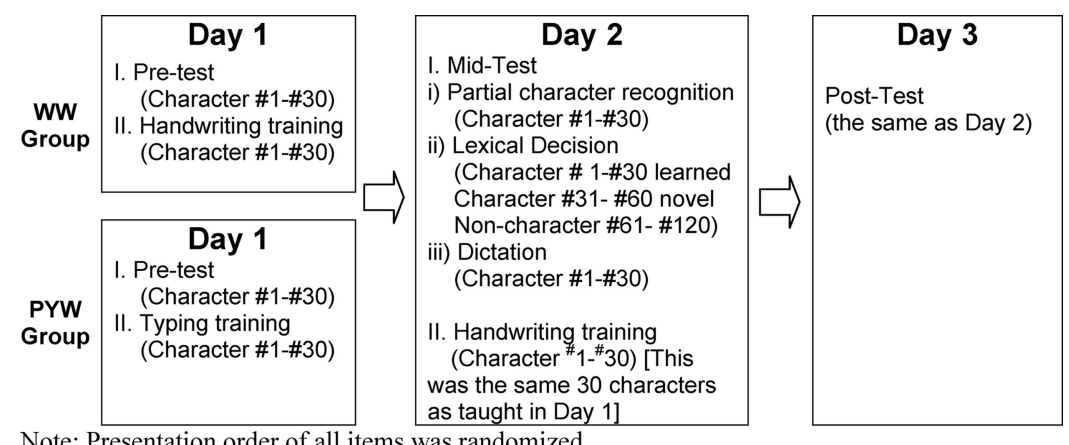

Figure 5. Design charts for Experiment 2. 
Table 2

Proportions of Correct Responses for 2 Testing Days Across Tasks Between Groups in Experiment 2

\begin{tabular}{|c|c|c|c|c|c|c|c|c|c|c|c|}
\hline \multirow{3}{*}{$\begin{array}{l}\text { Constituent } \\
\& \text { mapping }\end{array}$} & \multirow[b]{3}{*}{ Tasks } & \multicolumn{5}{|c|}{ After Day 1 training } & \multicolumn{5}{|c|}{ After Day 2 training } \\
\hline & & \multicolumn{2}{|c|}{ WW group writing } & \multicolumn{2}{|c|}{ PYW group typing } & \multirow{2}{*}{$\begin{array}{c}\text { Cohen's } \\
d\end{array}$} & \multicolumn{2}{|c|}{ WW group writing } & \multicolumn{2}{|c|}{ PYW group writing } & \multirow{2}{*}{$\begin{array}{c}\text { Cohen's } \\
d\end{array}$} \\
\hline & & Proportion & Variance & Proportion & Variance & & Proportion & Variance & Proportion & Variance & \\
\hline \multirow[t]{2}{*}{$\mathrm{O}$} & Lexical decision & .52 & .06 & .43 & .14 & $.55^{\mathrm{a}}$ & .62 & .09 & .59 & .14 & .20 \\
\hline & Partial recognition & .98 & .11 & .94 & .11 & $.46^{\mathrm{a}}$ & .99 & .12 & .97 & .07 & .20 \\
\hline $\mathrm{P}$ & Pinyin auditory dictation & .48 & .19 & .58 & .26 & $.55^{\mathrm{a}}$ & .47 & .26 & .62 & .18 & $.59^{\mathrm{a}}$ \\
\hline P-S & Auditory English-translation & .10 & .10 & .13 & .11 & $.63^{\mathrm{a}}$ & .12 & .12 & .16 & .12 & $.41^{\mathrm{a}}$ \\
\hline $\mathrm{O}-\mathrm{S}$ & English-translation & .43 & .19 & .24 & .18 & $.51^{\mathrm{a}}$ & .58 & .20 & .51 & .23 & $.41^{\mathrm{a}}$ \\
\hline \multirow[t]{2}{*}{$\mathrm{O}-\mathrm{P}$} & Pinyin segment & .30 & .16 & .41 & .17 & $.67^{\mathrm{a}}$ & .34 & .16 & .52 & .23 & $.74^{\mathrm{a}}$ \\
\hline & Tone & .28 & .13 & .32 & .20 & $.41^{\mathrm{a}}$ & .30 & .19 & .35 & .22 & .20 \\
\hline
\end{tabular}

Note. For WW group writing, $n=18$; for PYW group typing, $n=19$; for WW group writing, $n=18$; for PYW group writing, $n=19$. O $=$ orthography; $\mathrm{S}=$ semantics; $\mathrm{P}=$ phonology; $\mathrm{WW}$ group = writing + writing group; PYW group = Pinyin typing + writing group.

${ }^{a}$ Indicates that the strength of the association was statistically significant. We caculate Cohen's $d$ by using the following fomula: [4 $\left.\eta^{2} / 1-\eta^{2}\right]^{1 / 2}$.

was a marginally significant improvement from Day 1 to Day 2, $F(1,17)=2.762, M S E=0.033, p=.10, \eta^{2}=.03$.

Handwriting effect on orthography-semantics mapping. For the meaning task, group WW performed better than group PYW on Day $1, F(1,35)=6.98, M S E=1.53, p=.01, \eta^{2}=.06$, and on Day $2, F(1,35)=5.03, M S E=0.011, p=.027, \eta^{2}=.04$. The improvements from Day 1 to Day 2 were .15 for group WW and .27 for group PYW. The improvements from Day 1 to Day 2 were reliable for both groups: group WW, $F(1,17)=12.325$, $M S E=0.743, p<.001, \eta^{2}=.14$; group PYW, $F(1,18)=$ 14.921, MSE $=0.835, p<.001, \eta^{2}=.19$.

Pinyin-typing effect on phonological identification. For the Pinyin dictation task, the Pinyin-typing condition led to better performance on Day 1: group PYW (.58), group WW (.48), F(1, $35)=7.26, M S E=0.707, p=.008, \eta^{2}=.07$. After Day 2 training, group PYW (accuracy $=.62$ ) also did better than group $\mathrm{WW}($ accuracy $=.47), F(1,35)=5.81, M S E=0.488, p=.03$, $\eta^{2}=.08$. The improvement from Day 1 to Day 2 for group PYW was marginally reliable, $F(1,18)=3.68, p=.07, \eta^{2}=.07$, whereas group WW showed no gain $(F<1)$. Also on Day 2, group PYW (.62) outperformed group WW (.47), $F(1,58)=4.84$, $M S E=0.022, p=.03, \eta^{2}=.08$.

Writing and Pinyin-typing integration effect on phonologysemantics association. For the auditory English translation task, after Day 1 training, the two groups showed accuracies that were low and not different from each other, group $\mathrm{WW}=.10$ and group PYW $=.13, F(1,35)=1.07, M S E=0.019, p=.30, \eta^{2}=$ .09. After Day 2 training, group PYW performed better (.16) than group WW $(.12), F(1,35)=3.661, M S E=0.021, p=.045, \eta^{2}=$ .04 . However, the gains from Day 1 to Day 2 (.02 and .03 for the two groups) were modest and not different between groups.

Writing and Pinyin-typing integration effect on orthographyphonology association. Pinyin typing led to better identification of the spoken syllable associated with a character. After Day 1 training, given a character, group PYW showed greater accuracy (.41) than group WW (.30) in recalling its segments in Pinyin, $F(1$, $35)=14.5, M S E=.225, p=.001, \eta^{2}=.10$. On Day 2, following writing training, group PYW improved segment recall from Day 1 (from .41 to .52$), F(1,17)=16.5, M S E=0.129, p<.001, \eta^{2}=$ .12 , whereas the improvement for group WW (from .30 to .34) was not reliable $(F<1)$. For tone recall, the Pinyin-typing condition produced better performance after the first day's training: group PYW (.32), group WW (.28), $F(1,35)=4.03, M S E=0.021, p=$ $.022, \eta^{2}=.04$. But the performance on tone learning did not improve over the 2-day training for either group $(F \mathrm{~s}<1)$, nor was performance reliably different between groups after Day 2 training $\left(F_{\mathrm{S}}<1\right)$

Result summary. The Experiment 2 results include three major findings. First, there was a consistent writing effect between groups and over days. The effects of writing found in Experiment 1 on orthographic form recognition and orthography-semantics association were replicated in Experiment 2. In addition, the partial recognition task showed an effect of writing after the first day.

Second, there was a complementary effect of alphabetic coding. This Pinyin-typing effect was evidenced by the performance on two tasks, the auditory identification task and the Pinyin segment task of orthography-phonology mapping. In the auditory identification task, group PYW did better than group WW after Day 1 training, a result that reflected the role of phonological coding, which was supported in the typing training on Day 1 . In the orthography-phonology mapping task, group PYW did even better than group WW as represented by the improved performance on this task from Day 1 to Day 2.

\section{General Discussion}

\section{The Writing Effect}

The results of Experiment 1 and Experiment 2 confirm that the effects of writing on reading can occur with relatively modest writing opportunity. In Experiment 1, the adult learners of Chinese visually recognized characters more consistently and associated their forms with meanings more accurately in the handwriting condition than in the reading only condition. In Experiment 2, instruction through writing (group WW) produced better recognition performance than did instruction with Pinyin typing (group PYW) after Day 1 training. This difference disappeared as group PYW moved from Pinyin-typing training on Day 1 to handwriting training on Day 2, suggesting that even one session of handwriting can raise orthographic knowledge needed for recognition. 
To the best of our knowledge, this experiment is the first to directly assess the role of handwriting in orthographic recognition in adult Chinese beginners. Studies of native Chinese speakers have implicated a link between character writing and character recognition. For example, Tan et al. (2005) found a correlation between children's ability to copy characters and their later ability to read characters. More direct evidence for a role of writing in recognition comes from priming studies for Chinese characters (Flores d'Arcais, 1994) and in letter perception (Parkinson, Dyson, \& Khurana, 2010). Both studies showed that stroke fragments could prime characters in which they occurred when they were shown in the order in which they were written. This effect implies that information about written stroke order is part of the mental representation of a character. Recent studies with French prereaders (Longcamp et al., 2005) and adults (Longcamp et al., 2008) have found that letters or arbitrary characters learned through typing were subsequently recognized less accurately than letters or characters written by hand. Our study extends these writing-onreading effects to Chinese written language in an adult second language-learning context.

For either native speakers or for the second language learners of our studies, the advantage of handwriting may have a sensory-motor source. Writing provides a mental model of the written form that is accompanied by a new neural motor memory (Shadmehr \& Holcomb, 1997). As it becomes stabilized, motor memory can last for a very long period of time without any further practice (Shadmehr \& Brashers-Krug, 1997). Some studies even show an improvement of performance, without further practice, after consolidation of neural representation (Brashers-Krug, Shadmehr, \& Bizzi, 1996). As we noted earlier, writing also can direct attention directly to visual-spatial information, with or without a motor component.

Although a more specific explanation requires further research, the finding of an effect of writing on character reading across these two studies shows that handwriting (a) increases the quality of the orthographic form and (b) selectively strengthens the connection from orthography to meaning but not the connection from orthography to phonology, at least for this population of adult Chinese learners. Handwriting practice allows a tight coupling of visual with sensory-motor representations of Chinese writing but not of visual with speech-motor representations, as indicated by the results of both studies. Learners who are generally focused on meaning can use their orthographic knowledge of Chinese to complete the orthography-semantics association task. It is possible that the orthographic-phonology connection might be strengthened when the learners have higher spoken language skill.

This characterization of an effect of writing on the orthographic representation and on its link to meaning is reinforced by the fMRI study of Cao et al. (2010) with a different sample from the same population as in the present study. They found that temporal lobe areas associated with meaning processing, as well as visual-spatial and motor areas, were activated during character reading for characters trained with writing.

\section{The Pinyin Effect}

Pinyin provides an alphabetic coding system for Chinese that can help stabilize pronunciations. Experiment 2 demonstrates that learning characters through Pinyin-typing strengthens this link for adult learners and, more fundamentally, strengthens the phonolog- ical representation itself. Given a character, Pinyin-trained students were better able to identify its pronunciation than were writing-trained students. Moreover, after one session of training, students in the Pinyin-typing group (group PYW), compared with the writing group (group WW), were better able to specify the segments and tone of a spoken syllable from the training set. Both of these effects persisted even after both groups received only handwriting training the next day. These results suggest that even one session of Pinyin-typing training can strengthen phonological representations of spoken syllables as well as the connection from character to syllable.

However, compared with writing training, Pinyin training did not support character representation or links between character and meaning. When Pinyin trained learners switched to writing on the second day, they improved their ability to recognize characters from .21 (compared with .43 for group WW) to .51. These results are not surprising when the focus of training is on Pinyin rather than characters. Less expected is the relatively weak effect on the link between pronunciation and meaning. Presented with a spoken syllable from the training set, the Pinyin-trained group's accuracy in producing its English translation was .13 on Day 1 and .16 on Day 2. These accuracies are only modestly better than those of the writing-trained group (.10 and .12, respectively). This result suggests that Pinyin during training caused a focus on the phonological representation and its spelling, consistent with the assumption of alphabetic coding as support for phonology. This focus was not sufficiently in itself to sustain a stronger link from pronunciation to meaning. It is possible that adding a meaning component to the Pinyin training would support this linkage — for example, typing both the Pinyin and the English translation. It is also likely that with greater fluency in spoken language, the learner would be able to make these links because attention would not have to be exclusively directed to remembering an unfamiliar sound and trying to spell it.

There is also the question of the timing among the three constituents to be learned (character, spoken syllable, meaning). Presenting all three without sufficient time to process each one will interfere with learning (Solman \& Chung, 1996; Chung, 2002). Perhaps the 1-s interval between the spoken syllable and the English translation was not sufficient to allow all links to be acquired. However, any consideration of timing has to take into account efficiency (learning in relation to time) as well as absolute level of learning.

Also worth noting is that when learners in group PYW indicated the Pinyin segments and tone of a character, tone accuracy was lower than segment accuracy (Day 1, .32 compared with .41; Day 2, .35 compared with .52) despite a much higher chance rate for tone (1 of 4). Tone perception and memory is relatively difficult for learners whose first language is atonal, and our results are consistent with this fact. It is also true that Pinyin training supported tone performance somewhat better than writing training (.32 vs. .38 on Day 1$)$. In a study with this same adult population, Liu et al. (in press) found that combining Pinyin with practice on tones through the use of visual pitch contours was effective in supporting tone learning. The idea is that Pinyin presentation just prior to the spoken syllable helps to stabilize the representation of the segments, allowing attention to focus on the tonal contour when the syllable is presented. More generally, we think that Pinyin can function as a self-teaching tool (Share, 1995) for adult learners. For character reading, this selfteaching requires more effort, however, because its link to the character orthography is less systematic than it would be for alphabetic 
orthography. Seen as a self-teaching tool for phonology, the situation is different. Learning to write Pinyin in response to spoken syllables adds an alphabetic code that can help stabilize the phonological representation itself.

\section{Combining Handwriting With Pinyin-Typing}

Combining handwriting with Pinyin appears to be part of a sound instructional strategy for supporting the integration of phonology, orthographic form, and meaning, which is characteristic of skilled reading from the perspectives of Chinese linguistics (Halliday, 1984) and reading pedagogy (Leong, 1997), as well as from the empirical and theoretical perspective (Perfetti et al., 2005). After 2 days, students who had Pinyin instruction and then writing instruction performed as well as students who had 2 days of writing training on orthographic tasks and were better on phonological tasks. Thus, the combined training strengthened the orthographic (character) representation and the phonological representation. However, it did not produce stronger connections from these representations to meaning. Two days of writing led to better character-meaning connections than did the combined conditions. Furthermore, the combined conditions were not better in strengthening the phonology-meaning connections, which remained low in both conditions after 2 days. Thus, our instruction did not produce the full integration of all three lexical constituents (Liu, Guan, Chan, \& Perfetti, 2008), which implies that all pairwise connections between the three constituents are strong. Instead, we conclude that within the limits of the conditions we tested here, writing supports the orthographic representation and the link from orthography to meaning, and Pinyin supports the phonological representation and the connection between orthography and phonology. Each promotes a focused learning specific to the constituent that is the focus of instruction. What more is required for integration remains to be tested. Optimizing practice schedules for phonology and writing is one obvious consideration, as is the possibility of providing richer practices that require links to be made from writing and pronunciation to meaning. We also cannot rule out the possibility that more practice is part of the answer. Our training was regimen was modest, with 2 days of training.

\section{Comparison With English}

Finally, it is useful to consider the writing-on-reading effects we find in Chinese in relation to writing-reading correlations reported in alphabetic writing. Indeed, the writing-reading link is general across writing systems and has been studied in English in various ways. For example, studies have found a general correlation of spelling and reading in the early grades (Juel, Griffith, \& Gough, 1986) and broader linkages of cognitive, perceptual, and motor skills across reading and writing (Berninger, Cartwright, Yates, Swanson, \& Abbott, 1994). These correlations linkages in English rest on the alphabetic principle, which allows reciprocal connections between letters and phonemes. The case of Chinese character writing does not. In fact, the most direct comparison between English and Chinese is not our character writing condition, but our Pinyin typing condition. There, the students are practicing spelling what they hear, much as the case of spelling spoken English. This practice should support reading Pinyin just as spelling English should support reading English, but it cannot directly affect read- ing characters. The writing-on-reading effect in Chinese is exclusively about strengthening the graphic form of the character, which, we hypothesize, occurs by allowing the addition of a sensory-motor memory to visual form information.

\section{Conclusions}

We conclude that writing characters as part of learning to read them supports character reading. Both the behavioral studies reported here and the neuroimaging studies of Cao et al. (2010) with a comparable population provide evidence for an effect of writing on reading. We believe the key mechanism for this effect is the refinement of visual spatial information and the neuromotor memories that writing establishes, although the exact mechanism requires further research. Furthermore, this effect in adult second language learning was found with relatively modest practice at writing. We conclude also that whereas the writing effect is specific to knowledge of character form and its connection to meaning, the addition of alphabetic-coding through Pinyin training increases knowledge of the spoken forms that are connected to characters. A practical implication of the studies is that writing practice and Pinyin practice can be important parts of courses in Chinese to support more robust student learning of the spoken and written language.

\section{References}

Aleven, V., McLaren, B. M., Sewall, J., \& Koedinger, K. R. (2009). Example tracing tutors: A new paradigm for intelligent tutoring systems. International Journal of Artificial Intelligence in Education, 19, 105-154.

Berninger, V. W., Cartwright, A. C., Yates, C. M., Swanson, H. L., \& Abbott, R. D. (1994). Developmental skills related to writing and reading acquisition in the intermediate grades: Shared and unique functional systems. Reading and Writing, 6, 161-196. doi:10.1007/BF01026911

Bi, Y., Hai, Z., \& Zhang, Y. (2009). Reading does not depend on writing, even in Chinese. Neuropsychologia, 47, 1193-1199. doi:10.1016/ j.neuropsychologia.2008.11.006

Bowers, J. S., Davis, C. J., \& Hanley, D. A. (2005). Automatic semantic activation of embedded words: Is there a "hat" in that? Journal of Memory and Language, 52, 131-143. doi:10.1016/j.jml.2004.09.003

Brashers-Krug, T., Shadmehr, R., \& Bizzi, E. (1996, July). Consolidation in human motor memory. Nature, 382, 252-255. doi:10.1038/382252a0

Cao, F., Vu, M., Chan, D., Harris, L., Guan, Q. C., Xu, Y., \& Perfetti, C. A. (2010, November). Why does writing help reading in Chinese learning: Evidence from an fMRI study. Poster session presented at the Society for Neuroscience Conference, San Diego, CA.

Caramazza, A., \& Mahon, B. Z. (2006). The organization of conceptual knowledge in the brain: The future's past and some future directions. Cognitive Neuropsychology, 23, 13-38. doi:10.1080/02643290542000021

Chan, D. W., Ho C. S.-H., Tsang, S.-M., Lee, S.-H, \& Chung, K. K. H. (2006). Exploring the reading-writing connection in Chinese children with dyslexia in Hong Kong. Reading and Writing, 19, 543-561. doi: $10.1007 / \mathrm{s} 11145-006-9008-\mathrm{z}$

Chinese Language Committee. (2009). Modern Chinese common character list (Hanyu Tongyong Zibiao). Beijing, China: Commercial Press.

Chung, K. K. H. (2002). Effective use of Hanyu Pinyin and English translations as extra stimulus prompts on learning of Chinese characters. Educational Psychology, 22, 149-164. doi:10.1080/01443410120115238

DeFrancis, J. (1989). Visible speech: The diverse oneness of writing systems. Honolulu, HI: University of Hawaii Press.

Flores d'Arcais, G. B. (1994). Order of strokes writing as a cue for retrieval in reading Chinese characters. European Journal of Cognitive Psychology, 6, 337-355. doi:10.1080/09541449408406519 
Fredlein, S., \& Fredlei, P. (1994). An introduction to Chinese. Brisbane, Australia: China Soft.

Halliday, M. A. K., (1981). Readings in systemic linguistics. London, England: Batsford

Huang, H.-S., \& Hanley, J. R. (1997). A longitudinal study of phonological awareness, visual skills, and Chinese reading acquisition amongst first graders in Taiwan. International Journal of Behavioral Development, 20, 249-268. doi:10.1080/016502597385324

Institute of Linguistics, Chinese Academy of Social Sciences. (2004). Xinhua dictionary (10th ed.). Beijing, China: Commercial Press.

Juel, C., Griffith, P., \& Gough, P. (1986). Acquisition of literacy: A longitudinal study of children in first and second grade. Journal of Educational Psychology, 78, 243-255. doi:10.1037/0022-0663.78.4.243

Kosslyn, S. M., Cave, C. B., Provost, D., \& Von Gierke, S. (1988). Sequential processes in image generation. Cognitive Psychology, 20, 319-343. doi:10.1016/0010-0285(88)90002-3

Kučera, H., \& Francis, W. (1967). Computational analysis of present-day American English. Providence, RI: Brown University Press.

Leong, C. H. (1997). Paradigmatic analysis of Chinese word reading: Research findings and classroom practices. In C. K. Leong \& R. M. Joshi (Eds.), Cross-language studies of learning to read and spell (pp. 1-30). Amsterdam, the Netherlands: Kluwer.

Lin, D., McBride-Chang, C., Shu, H., Zhang, Y., Li, H., Zhang, J., Aram, D., \& Levin, I. (2010). Small wins big: Analytic Pinyin skills promote Chinese word reading. Psychological Science, 21, 1117-1122. doi: 10.1177/0956797610375447

Liu, Y., Guan, C. Q., Chan, H.-L., \& Perfetti, C. A. (2008, June). The effect of character-writing on reading skill development: An experiment in Chinese. Paper presented at the International Conferences on Cognitive Science, Moscow, Russia.

Liu, Y. Wang, M. Perfetti, C., Brubaker, B., Wu, S., \& MacWhinney, B. (in press). Learning a tonal language by attending to the tone: An in-vivo experiment. Language Learning.

Longcamp, M., Boucard, C., Gilhodes, J.-C., Anton, J.-L., Roth, M., Nazarian, B., \& Velay, J.-L., (2008). Learning through hand- or typewriting influence visual recognition of new graphic shapes: Behavioral and functional imaging evidence. Journal of Cognitive Neuroscience, 20, 802-815. doi:10.1162/jocn.2008.20504

Longcamp, M., Zerbato-Poudou, M. T., \& Velay, J. L. (2005). The influence of writing practice on letter recognition in preschool children: A comparison between handwriting and typing. Acta Psychologica, 119, 67-79. doi:10.1016/j.actpsy.2004.10.019

Packard, J. L., Chen, X., Li, W.-L., Wu, X.-C., Gaffney, J. S., Li, H., \& Anderson, R. C. (2006). Explicit instruction in orthographic structure and word morphology helps Chinese children learn to write characters. Reading and Writing, 19, 457-487. doi:10.1007/s11145-006-9003-4

Parkinson, J., Dyson, B. J., \& Khurana, B. (2010). Line by line: The ERP correlates of stroke order priming in letters. Experimental Brain Research, 201, 575-586.

Perfetti, C. A. (2007). Reading ability: Lexical quality to comprehension. Scientific Studies of Reading, 11, 357-383.

Perfetti, C. A., \& Hart, L. (2002). The lexical quality hypothesis. In L. Vehoeven, C. Elbro, \& P. Reitsma (Eds.), Precursors of functional literacy (pp. 189-213). Amsterdam, the Netherlands: Benjamins.

Perfetti, C. A., Liu, Y., \& Tan, L. H. (2005). The lexical constituency model: Some implications of research on Chinese for general theories of reading. Psychological Review, 112, 43-59. doi:10.1037/0033295X.112.1.43
Perfetti, C. A., \& Tan, L. H. (1998). The time-course of graphic, phonological, and semantic activation in Chinese character identification Journal of Experimental Psychology: Learning, Memory, and Cognition, 24, 101-118. doi:10.1037/0278-7393.24.1.101

Perfetti, C. A., Zhang, S., \& Berent, I. (1992). Reading in English and Chinese: Evidence for a "universal" phonological principle. In R. Frost (Ed.), Orthography, phonology, morphology, and meaning (pp. 227-248). Amsterdam, the Netherlands: North-Holland. doi:10.1016/S0166-4115(08)62798-3

Rayner, K., Foorman, B. R., Perfetti, C. A., Pesetsky, D., \& Seidenberg, M. S. (2001). How psychological science informs the teaching of reading. Psychological Science in the Public Interest, 2, 31-74. doi:10.1111/ 1529-1006.00004

Ricketts, J., Bishop, D. V. M., \& Nation, K. (2009). Orthographic facilitation in oral vocabulary acquisition. The Quarterly Journal of Experimental Psychology, 62, 1948-1966. doi:10.1080/17470210802696104

Shadmehr, R., \& Brashers-Krug, T. (1997). Functional stages in the formation of human long-term motor memory. The Journal of Neuroscience, 17, 409-419.

Shadmehr, R., \& Holcomb, H. H. (1997, August). Neural correlates of motor memory consolidation. Science, 277, 821-825. doi:10.1126/ science.277.5327.821

Share, D. L. (1995). Phonological recoding and self-teaching: Sine qua non of reading acquisition. Cognition, 55, 151-218. doi:10.1016/00100277(94)00645-2

Siok, W. T., Niu, Z. Jin, Z., Perfetti, C. A., \& Tan, L. H. (2008). A structural-functional basis for dyslexia in the cortex of Chinese readers. Proceedings of the National Academy of Sciences USA, 105, 5561-5566.

Solman, R. T., \& Chung, K. K. H. (1996). Language transfer and blocking in second language vocabulary learning. Journal of Behavioral Education, 6, 173-190. doi:10.1007/BF02110231

Taft, M., Zhu, X., \& Peng, D. (1999). Positional specificity of radicals in Chinese character recognition. Journal of Memory and Language, 40, 498-519. doi:10.1006/jmla.1998.2625

Tan, L. H., Spinks, J. A., Eden, G., Perfetti, C. A., \& Siok, W. T. (2005). Reading depends on writing, in Chinese. Proceedings of the National Academy of Sciences USA, 102, 8781-8785. doi:10.1073/ pnas.0503523102

Vellutino, F. R., Fletcher, J. M., Snowling, M. J., \& Scanlon, D. M. (2004). Specific reading disability (dyslexia): What have we learned in the past four decades? Journal of Child Psychology and Psychiatry, 45, 2-40. doi:10.1046/j.0021-9630.2003.00305.x

Wang, M., Perfetti, C. A., \& Liu, Y. (2003). Alphabetic readers quickly acquire orthographic structure in learning to read Chinese. Scientific Studies of Reading, 7, 183-208. doi:10.1207/S1532799XSSR0702_4

Wang, W. S.-Y. (1973). The Chinese language. Scientific American, 228, 50-60. doi:10.1038/scientificamerican0273-50

Wu, S., Yu, Y., Zhang, Y., \& Tian, W. (2005). Chinese link: Zhongwen Tiandi (Elementary Chinese). Upper Saddle River, NJ: Prentice Hall.

Yin, B., \& Rohsenow, J. S. (1994). Modern Chinese characters. Beijing, China: Sinolingua.

Ziegler, J. C., Bertrand, D., Toth, D., Csepe, V., Reis, A., Faisca, L., . . . Blomert, L. (2010). Orthographic depth and its impact on universal predictors of reading: A cross-language investigation. Psychological Science, 21, 551-559. doi:10.1177/0956797610363406

Ziegler, J. C., \& Goswami, U. (2005). Reading acquisition, developmental dyslexia, and skilled reading across languages: A psycholinguistic grain size theory. Psychological Bulletin, 131, 3-29. doi:10.1037/0033-2909.131.1.3 
Appendix

Study Materials for Experiment 1 and Experiment 2

\begin{tabular}{|c|c|c|c|c|c|}
\hline Item & Condition code & Matched set & Configuration & $\begin{array}{l}\text { Number } \\
\text { of strokes }\end{array}$ & $\begin{array}{l}\text { English } \\
\text { translation } \\
\text { frequency }\end{array}$ \\
\hline 聊 & 1 & 1 & 1 & 12 & 5 \\
\hline 航 & 2 & 1 & 1 & 10 & 1 \\
\hline 特 & 3 & 1 & 1 & 10 & 9 \\
\hline 租 & 1 & 2 & 1 & 10 & 21 \\
\hline 鼓 & 2 & 2 & 1 & 13 & 11 \\
\hline 頂 & 3 & 2 & 1 & 11 & 12 \\
\hline 親 & 1 & 3 & 1 & 16 & 17 \\
\hline 鏡 & 2 & 3 & 1 & 18 & 27 \\
\hline 澡 & 3 & 3 & 1 & 16 & 27 \\
\hline 胸 & 1 & 4 & 1 & 10 & 56 \\
\hline 務 & 2 & 4 & 1 & 10 & 84 \\
\hline 維 & 3 & 4 & 1 & 14 & 60 \\
\hline 瓶 & 1 & 5 & 1 & 10 & 76 \\
\hline 夠 & 2 & 5 & 1 & 11 & 66 \\
\hline 旅 & 3 & 5 & 1 & 10 & 62 \\
\hline 彈 & 1 & 6 & 1 & 16 & 205 \\
\hline 牆 & 2 & 6 & 1 & 17 & 173 \\
\hline 價 & 3 & 6 & 1 & 15 & 207 \\
\hline 陰 & 1 & 7 & 1 & 11 & 9 \\
\hline 抽 & 2 & 7 & 1 & 8 & 6 \\
\hline 殉 & 3 & 7 & 1 & 10 & 6 \\
\hline 戲 & 1 & 8 & 1 & 17 & 47 \\
\hline 鐘 & 2 & 8 & 1 & 20 & 18 \\
\hline 聽 & 3 & 8 & 1 & 21 & 51 \\
\hline 所 & 1 & 9 & 1 & 8 & 205 \\
\hline 秋 & 2 & 9 & 1 & 9 & 150 \\
\hline 低 & 3 & 9 & 1 & 7 & 217 \\
\hline 醫 & 1 & 10 & 2 & 18 & 32 \\
\hline 盤 & 2 & 10 & 2 & 15 & 18 \\
\hline 幣 & 3 & 10 & 2 & 15 & 12 \\
\hline 麗 & 1 & 11 & 2 & 19 & 127 \\
\hline
\end{tabular}


Appendix (continued)

\begin{tabular}{|c|c|c|c|c|c|}
\hline Item & Condition code & Matched set & Configuration & $\begin{array}{l}\text { Number } \\
\text { of strokes }\end{array}$ & $\begin{array}{l}\text { English } \\
\text { translation } \\
\text { frequency }\end{array}$ \\
\hline 雙 & 2 & 11 & 2 & 18 & 84 \\
\hline 赞 & 3 & 11 & 2 & 19 & 97 \\
\hline 幫 & 1 & 12 & 2 & 17 & 325 \\
\hline 熱 & 2 & 12 & 2 & 15 & 137 \\
\hline 览 & 3 & 12 & 2 & 21 & 237 \\
\hline 算 & 1 & 13 & 2 & 14 & 4 \\
\hline 慕 & 2 & 13 & 2 & 14 & 10 \\
\hline 營 & 3 & 13 & 2 & 17 & 1 \\
\hline 疼 & 1 & 14 & 2 & 10 & 91 \\
\hline 屍 & 2 & 14 & 2 & 9 & 7 \\
\hline 扇 & 3 & 14 & 2 & 8 & 18 \\
\hline 處 & 1 & 15 & 2 & 11 & 589 \\
\hline 歲 & 2 & 15 & 2 & 13 & 242 \\
\hline 歷 & 3 & 15 & 2 & 16 & 972 \\
\hline 究 & 1 & 16 & 2 & 7 & 247 \\
\hline 景 & 2 & 16 & 2 & 12 & 187 \\
\hline 管 & 3 & 16 & 2 & 13 & 102 \\
\hline 率 & 1 & 17 & 2 & 11 & 222 \\
\hline 感 & 2 & 17 & 2 & 13 & 216 \\
\hline 嘗 & 3 & 17 & 2 & 13 & 276 \\
\hline 零 & 1 & 18 & 2 & 13 & 27 \\
\hline 翼 & 2 & 18 & 2 & 17 & 98 \\
\hline 鬆 & 3 & 18 & 2 & 18 & 62 \\
\hline 邊 & new & 19 & 3 & 18 & 78 \\
\hline 壏 & new & 19 & 3 & 16 & 41 \\
\hline 新 & new & 20 & 1 & 13 & 1,315 \\
\hline 須 & new & 20 & 1 & 12 & 1,013 \\
\hline
\end{tabular}

Note. In Experiment 1, 54 characters in 1-18 matched sets were used. Characters indicated by Condition Code 1 were taught in the reading only condition, and those indicated by Condition Code 2 were taught in the handwriting condition; characters indicated by Condition Code 3 were used only as novel stimuli assessed in lexical decision task. In Experiment 2, all 36 characters with Condition Codes 1 and 2 and four new characters were used. For the configuration, $1=$ left-right, 2 = upper-bottom, and $3=$ inside-outside. English translation frequency is based on Kučera \& Francis (1967).

Received May 14, 2010 